\title{
Microstructure and texture evolution during annealing a cryogenic-SPD processed Al-alloy with a nanoscale lamellar HAGB grain structure
}

\author{
G.H. Zahid ${ }^{1}$, Y. Huang, P.B. Prangnell ${ }^{*}$ \\ Manchester Materials Science Centre, The University of Manchester, Grosvenor Street, Manchester M17HS, UK
}

Received 23 January 2009; received in revised form 1 April 2009; accepted 7 April 2009

Available online 9 May 2009

\begin{abstract}
The grain structure and texture evolution during annealing a Al-0.13\% Mg submicron-grained alloy, deformed by plane-strain compression (PSC) at cryogenic temperatures, has been investigated by transmission electron microscopy and electron backscatter diffraction. After deformation the alloy contained a lamellar grain structure with a high-angle grain boundary (HAGB) spacing of $190 \mathrm{~nm}$ and an area fraction of $\sim 80 \%$. On annealing the grain structure coarsened and transformed from lamellar to equiaxed. Remarkably, the fraction of low-angle grain boundaries (LAGBs) progressively increased during annealing, to $\sim 50 \%$ above $300{ }^{\circ} \mathrm{C}$, leading to instability and discontinuous recrystallization at higher temperatures. This resulted in a "bimodal grain structure" comprised of bands of coarser grains and fine subgrains, arising as a result of the increase in proportion of lower-mobility LAGBs. The surprisingly large increase in LAGB fraction on annealing is shown to be related to orientation impingement, originating from the strong texture present after PSC in liquid nitrogen.
\end{abstract}

(C) 2009 Acta Materialia Inc. Published by Elsevier Ltd. All rights reserved.

Keywords: Severe plastic deformation (SPD); Nanocrystalline; Cryogenic deformation; Grain growth; Continuous recrystallisation

\section{Introduction}

There is currently considerable interest in the development of ultrafine-grained (UFG) metals with submicron, or nanograined, structures (e.g. [1-28]). The rationale for this research stems from the Hall-Petch theory, which predicts that the strength of an alloy is inversely proportional to the square root of its grain size [1-3]. However, there are also benefits in certain applications from the increase in fine-scale homogeneity and high-angle boundary area that results from grain size reduction to the nanoscale. Although various methods can be used to produce materials with grain sizes in the range of $10-1000 \mathrm{~nm}$, severe plastic deformation (SPD) has the advantage of being a "top-

\footnotetext{
* Corresponding author. Tel.: +44 161200 3610; fax: +44 1612003586. E-mail address: philip.prangnell@manchester.ac.uk (P.B. Prangnell).

${ }^{1}$ Present address: NMD, PINSTECH, PO Nilore, Islamabad, Pakistan.
}

down" approach, involving grain refinement from a bulk billet by ultra-high-strain deformation [3-7]. SPD is thus free from the problems of residual porosity and contamination that are frequently encountered in nanograined materials produced via bottom-up techniques, requiring, for example, the consolidation of fine powders.

An important disadvantage of SPD is that the rate of grain refinement becomes increasingly inefficient with strain and ultimately a limit is approached at plastic strains greater than $\sim 10$ [8-11]. Recently, it has been confirmed that the steady-state grain size at ultra-high strains is a result of dynamic recovery operating at surprisingly low homologous temperatures $[10,12]$. As recovery processes are thermally activated, reducing the deformation temperature is an effective way to suppress dynamic recovery and decrease the attainable grain size. Many researchers have attempted to use this strategy to develop nanograin structures by SPD, using techniques like cryogenic rolling 
at temperature as low as $77 \mathrm{~K}$ [12-15]. Work by the current authors [12], has shown that plane-strain compression (PSC) of submicron-grained aluminium in liquid nitrogen can result in grain structures approaching $100 \mathrm{~nm}$ in thickness, containing high fractions of high-angle grain boundary (HAGB) area $(>70 \%)$. However, the as-deformed materials are anisotropic, have a strong texture, and typically contain lamellar HAGB structures, with many retained low-angle grain boundaries (LAGBs). It was further found that the cryogenically deformed materials were unstable even at room temperature, slowly coarsening statically, but exhibiting rapid dynamic grain growth [12]. This is not surprising, as with a $100 \mathrm{~nm}$ grain size the driving pressure for grain coarsening due to surface tension is of the order of $10 \mathrm{MPa}$ [16].

Despite the high level of interest in nanograined metals, a full understanding of their annealing behaviour is currently lacking in the literature. To date a range of phenomena has been reported, including: extended recovery, spheroidization, uniform coarsening, discontinuous coarsening (resulting in bimodal grain structures) and recrystallization (e.g. [13,14,16-27]). In some cases materials exhibit room temperature coarsening [26], or stability up to higher temperatures [27]. A possible reason for the diverse phenomena observed is the diverse nature of the materials investigated and the different deformation structures obtained by varying processing conditions. Of particular interest are the mechanisms behind the formation of finescale bimodal grain structures on annealing cryogenically deformed metals, which have been claimed to result in nanograined matrix materials with the attractive property that they combine high strength with good ductility $[14,15]$.

The aim of the present study was to clarify some of these issues by investigating in detail the microstructure and texture evolution during annealing a single-phase model aluminium alloy, containing a nanoscale lamellar grain structure, produced by cryogenic-SPD. The material was first deformed by equal channel angular extrusion (ECAE) at room temperature to obtain a submicron starting grain structure, followed by PSC in liquid nitrogen. The microstructure and texture evolution during annealing were analyzed in detail by high-resolution electron backscatter diffraction (EBSD) and transmission electron microscopy (TEM).

\section{Materials and methods}

A direct-chill cast $\mathrm{Al}-0.13 \mathrm{wt} . \% \mathrm{Mg}$ alloy, produced from high-purity feed stock and containing no second-phase particles, was used for the present investigation. The alloy was cold rolled $50 \%$ and recrystallized, giving a starting grain size of $\sim 300 \mu \mathrm{m}$. Square cross-section billets $(100 \mathrm{~mm} \times$ $15 \mathrm{~mm}^{2}$ ) were machined in the rolling direction and preprocessed by ECAE, using route $\mathrm{A}$ [28], with a $120^{\circ}$ die at $298 \mathrm{~K}$, to a total effective strain of $\sim 10\left(15\right.$ passes; $\left.\dot{\varepsilon}=0.3 \mathrm{~s}^{-1}\right)$ resulting in a submicron grain size of $\sim 0.9 \mu \mathrm{m}$. PSC specimens were cut from the ECAE billets and deformed in a channel die at liquid nitrogen temperatures to a true strain of $\varepsilon_{\mathrm{tr}}=1.5\left(\hat{\varepsilon}=10^{-2} \mathrm{~s}^{-1}\right)$. During PSC the specimen normal direction (ND), transverse (TD) and rolling direction (RD) were aligned parallel to ND, TD and the extrusion direction (ED) in the ECAE billet, respectively. Channel die PSC was chosen to simulate rolling under more controllable conditions of constant temperature and strain rate. The PSC rig and samples were immersed in liquid nitrogen at a temperature of $77 \pm 2 \mathrm{~K}$. Molybdenum disulphide was used to minimize friction during compression.

To investigate their thermal stability, the deformed samples were annealed at a range of temperatures, from 100 to $400{ }^{\circ} \mathrm{C}$ for $1 \mathrm{~h}$, as well as isothermally at $250^{\circ} \mathrm{C}$. Microstructural and hardness changes were recorded for each temperature. The deformed samples were sectioned in two orientations through their centre, parallel to the ND-RD and ND-TD planes, before metallographic preparation and electropolishing. Their microstructures and textures were characterized by high-resolution EBS imaging and EBSD orientation mapping in an FEI Sirion FEGSEM, fitted with an HKL-EBSD system. The spatial and angular resolution of the EBSD system was $\sim 10 \mathrm{~nm}$ and $\sim 1^{\circ}$, respectively [29]. In the EBSD maps presented, HAGBs are shown by black lines and have misorientations $\geqslant 15^{\circ}$, while LAGBs are depicted by light grey lines and have misorientations $<15^{\circ}$. To avoid misorientation noise, boundaries were cut-off at less than $1.5^{\circ}$. Average linear intercept measurements of the HAGB and LAGB spacing were made in $\mathrm{ND}\left(\lambda_{\mathrm{ND}}\right), \mathrm{RD}\left(\lambda_{\mathrm{RD}}\right)$ and $\mathrm{TD}\left(\lambda_{\mathrm{TD}}\right)$. Where the structure was highly elongated in RD (i.e. at low temperatures), $\lambda_{\mathrm{RD}}$ was measured manually to improve accuracy. The average fraction of HAGB area, boundary misorientation distributions and texture were obtained from the EBSD data from the ND-RD and ND-TD planes. All statistical boundary data was averaged over at least three maps and 2000 grains, with the step size set to less than $10 \%$ of the map minimum cell size. Texture measurements were made on large area, bigger step size maps. Volume fractions $\left(f_{\mathrm{V}}\right)$ of the main texture components were obtained allowing an angular spread of $15^{\circ}$ from the ideal orientations. Thin foils for TEM examination were prepared using conventional jet polishing in the ND-RD plane. Vickers microhardness measurements were made with an applied load of $30 \mathrm{~g}$.

\subsection{Definition of terms}

Because of the high fraction of HAGBs in severely deformed alloys, there is often some confusion in the literature as to the distinction between "grains" and substructure. Although we will be initially talking about microstructures, where the HAGBs present were formed by deformation processes, after severe deformation the HAGB spacing is typically considerably less than the LAGB spacing $[5,11]$. We will thus refer to volumes within the deformed state having a HAGB perimeter greater than $15^{\circ}$ in misorientation as "grains". The grain dimensions referred to are the HAGB 
linear intercept distance in ND (thickness), RD (length) and TD (width). Similarly, subgrains will refer to volumes with a LAGB perimeter and cells the minimum scale microstructural unit enclosed by a boundary irrespective of its misorientation. The cell size is therefore the minimum boundary spacing given by the linear intercept across all boundaries.

\section{Results}

\subsection{Grain structure of the as-deformed starting material}

The ultrafine grain structures formed after ECAE processing the $\mathrm{Al}-0.1 \% \mathrm{Mg}$ alloy at room temperature have been previously reported $[5,11,30]$. Processing by route A, to this strain level, leads to a fibrous deformation structure aligned close to ED, containing a mixture of elongated thin ribbon grains and lower-aspect-ratio submicron grains.
The deformation structure had an average grain thickness $\lambda_{\mathrm{ND}}$ of $\sim 0.6 \mu \mathrm{m}$, aspect ratio of $\sim 2.3$, and a HAGB area fraction of $\sim 75 \%$. The texture after ECAE is relatively weak and was comprised of rotated cube $\left(\left\{\begin{array}{lll}0 & 0 & 1\end{array}\right\}\left\langle\begin{array}{llll}1 & 1 & 0\end{array}\right)\right.$ and $\left\{\begin{array}{llllll}1 & 1 & 2\end{array}\right\}\left\langle\begin{array}{llll}1 & 1 & 0\end{array}\right\rangle$ components $[11,12]$. It has previously been shown that little further grain subdivision occurs when the ECAE preprocessed submicron-grained material is deformed in PSC at $77 \mathrm{~K}$. The HAGB spacings in RD and ND simply followed the geometrically expected behaviour, from the imposed strain tensor, until a new steadystate grain width was approached limited by dynamic recovery [12]. The corresponding compression in $\lambda_{\mathrm{ND}}$ and extension in $\lambda_{\mathrm{RD}}$ resulted in a high-aspect-ratio, extremely fine lamellar HAGB structure.

Figs. 1a and 2a show the deformation structure of the Al- $0.13 \% \mathrm{Mg}$ alloy after PSC at $77 \mathrm{~K}$ to a strain of $\varepsilon_{\text {true }}=1.5$ by scanning electron microscopy, EBSD and
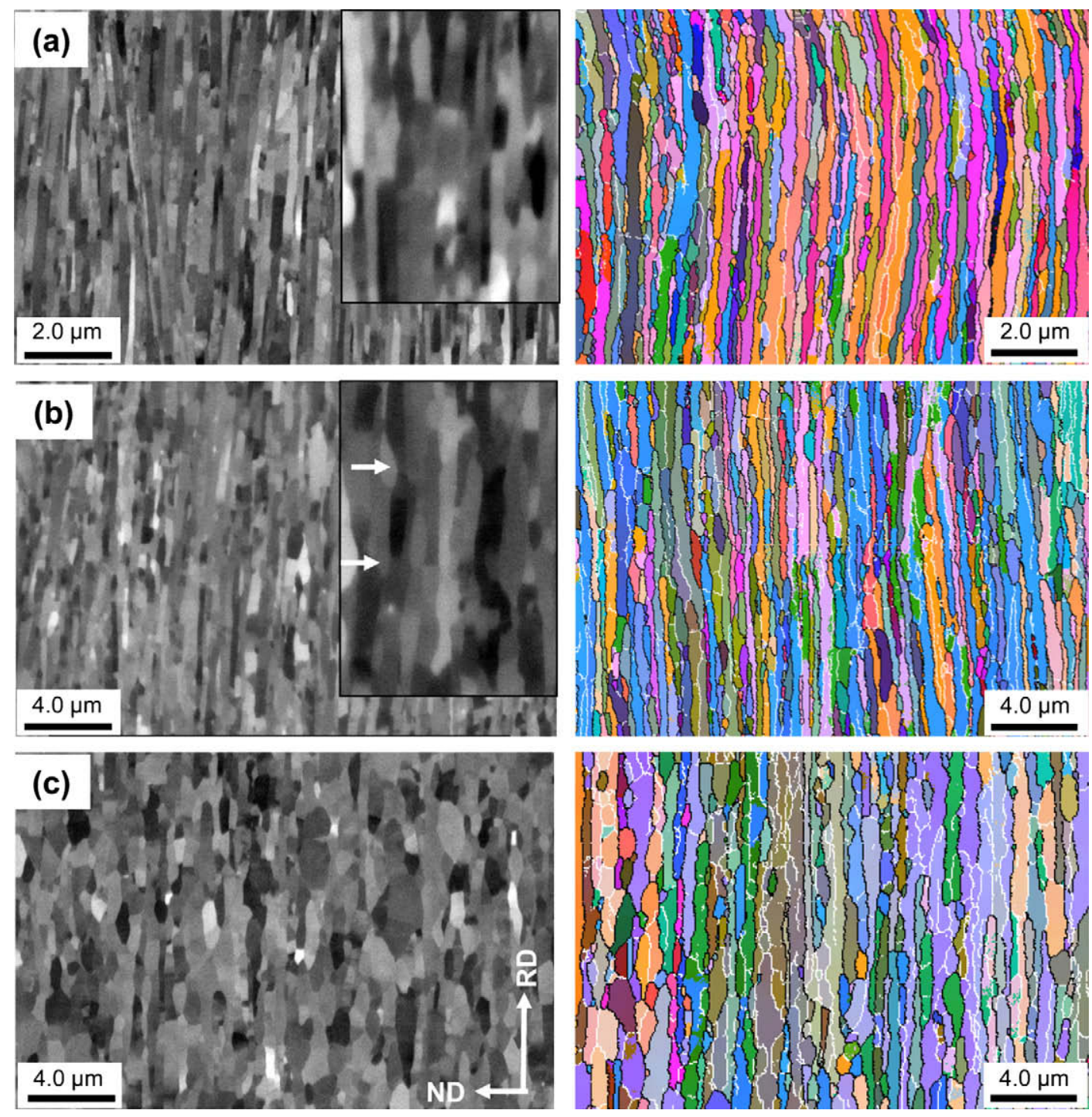

Fig. 1. Backscattered electron images, with magnified inserts, and EBSD maps of the grain structure of the Al-0.13\% Mg alloy, from the RD-ND plane: (a) after plane-strain compression (PSC) in liquid nitrogen and (b and c) following annealing for $1 \mathrm{~h}$ at 130 and $150{ }^{\circ} \mathrm{C}$. In the EBSD maps black and light grey lines depict high- and low-angle boundaries, respectively. Note the different scales necessary because of the large range of grain sizes. 

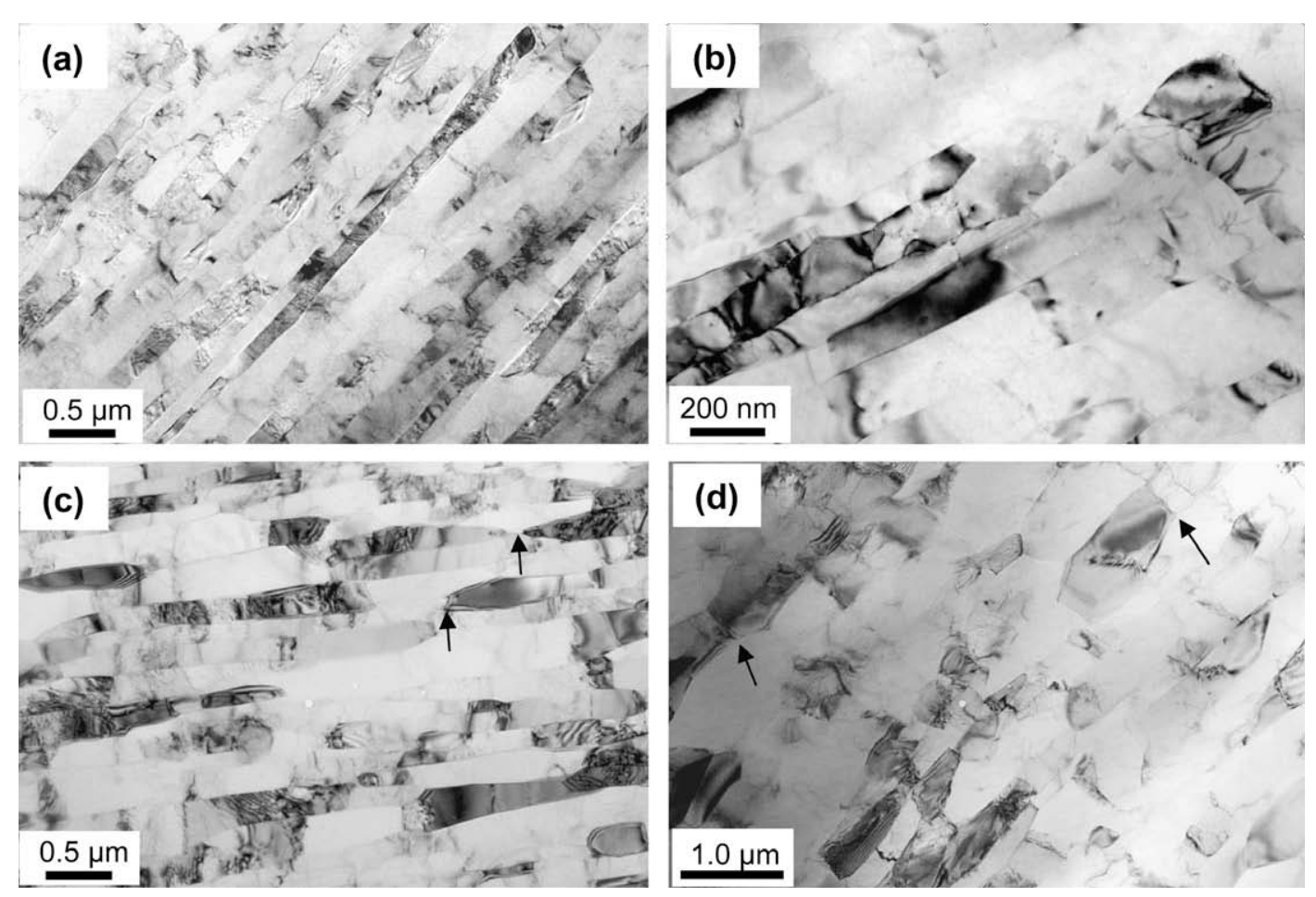

Fig. 2. Typical TEM mages of the Al-0.13\% Mg alloy (RD-ND plane): (a and b) low and higher magnification, after plane-strain compression in liquid nitrogen and ( $\mathrm{b}$ and c) following annealing for $1 \mathrm{~h}$ at 130 and $150{ }^{\circ} \mathrm{C}$.

TEM. The microstructure consists of lamellar grains aligned in the rolling direction. The average boundary spacing in ND (including both LAGBs and HAGBs) was $140 \mathrm{~nm}$ and is close to the nanoscale $(<100 \mathrm{~nm})$. However, the ND HAGB spacing for boundaries $\geqslant 15^{\circ}$ in misorientation, or grain thickness, was $\sim 190 \mathrm{~nm}$. In comparison the average HAGB spacing in $\mathrm{RD}$, or grain length, was considerably larger and estimated to be $\sim 1.5 \mu \mathrm{m}$, giving an aspect ratio of $\lambda_{\mathrm{RD}} / \lambda_{\mathrm{ND}} \sim 8$, with some ribbon grains extending for up to $10 \mu \mathrm{m}$. A small fraction of finer, lowaspect-ratio grains was observed along the lamellar boundaries and at the ends of the lamellar grains (see Fig. 1a). The deformation structure also contained some larger grain fragments, or strongly textured bands, containing primarily low-angle boundaries, including internal lowangle lamellar boundaries (Fig. 1a). In extreme cases these bands were up to $2 \mu \mathrm{m}$ wide.

TEM images (Fig. 2) showed that the lamellar grains contained a low density of statistically stored dislocations, but more transverse LAGBs than could be identified in the EBSD maps, due to the presence of boundaries lower in misorientation than the orientation noise cut-off employed $\left(1.5^{\circ}\right)$. Nevertheless, it was still evident from the backscattered electron and TEM images that the transverse LA boundary spacing was greater than the lamellar thickness (190 nm), being on average $\sim 300 \mathrm{~nm}$. Furthermore, some of the thinnest ribbon grains contained very few transverse boundaries (arrowed in BS image Fig. 1a). The fraction of HAGB area measured by EBSD after cryogenic deformation was $\sim 83 \%$. However, if the undetected $<1.5^{\circ}$ misorien- tation boundaries are taken into account, this figure would fall to $\sim 70 \%$. When viewed in the ND-TD plane (Fig. 3a), the lamellar grains were also elongated in TD following PSC, with an average width of $330 \mathrm{~nm}$ and a $\lambda_{\mathrm{TD}} / \lambda_{\mathrm{ND}}$ aspect ratio of $\sim 2$. After cryogenic deformation the lamellar deformation structure could, therefore, be described as comprised of grains with a ribbon-, or lath-like, morphology.

\subsection{Microstructure evolution during annealing}

The effect of $1 \mathrm{~h}$ isochronal annealing treatments on the microstructure evolution of the cryogenically deformed samples was studied up to $400{ }^{\circ} \mathrm{C}$. In Fig. 4 a hardness curve for the samples after annealing is plotted as a function of temperature. Two regimes can be seen: at low temperatures up to $150{ }^{\circ} \mathrm{C}$ there is a gradual decrease, whereas above $150^{\circ} \mathrm{C}$ a more dramatic reduction occurs. Without any knowledge of the mechanisms involved, this data could be interpreted as being characteristic of recovery at low temperatures, followed by more rapid softening at higher temperatures due to grain coarsening, or recrystallization, involving HAGB migration.

\subsubsection{Low-temperature annealing}

After annealing at $100{ }^{\circ} \mathrm{C}$ the microstructure was similar to that seen for the deformed condition, although there was already a significant increase in the HAGB spacing in $\lambda_{\mathrm{ND}}$ from 190 to $240 \mathrm{~nm}$ (Fig. 2b, etc.). Coarsening of the grain structure rapidly accelerated above $100{ }^{\circ} \mathrm{C}$. On annealing 

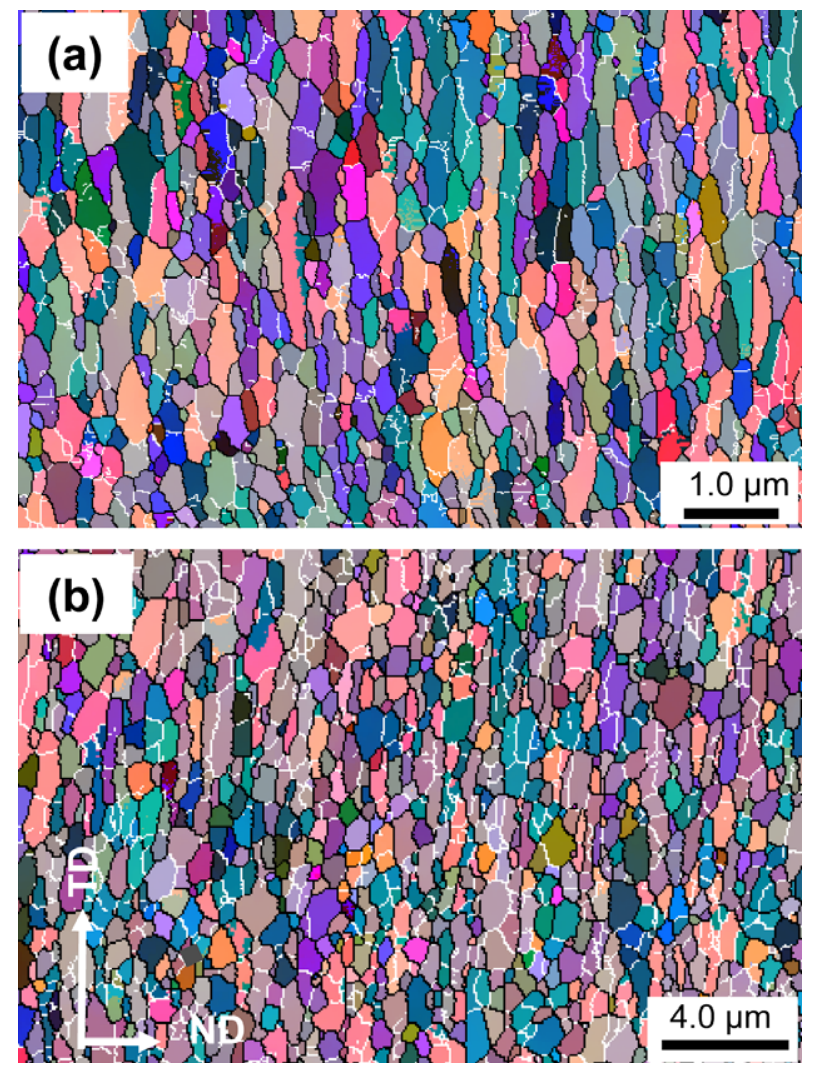

Fig. 3. EBSD maps of the grain structure from the TD-ND plane: (a) after plane-strain compression in liquid nitrogen and (b) following annealing for $1 \mathrm{~h}$ at $130^{\circ} \mathrm{C}$.

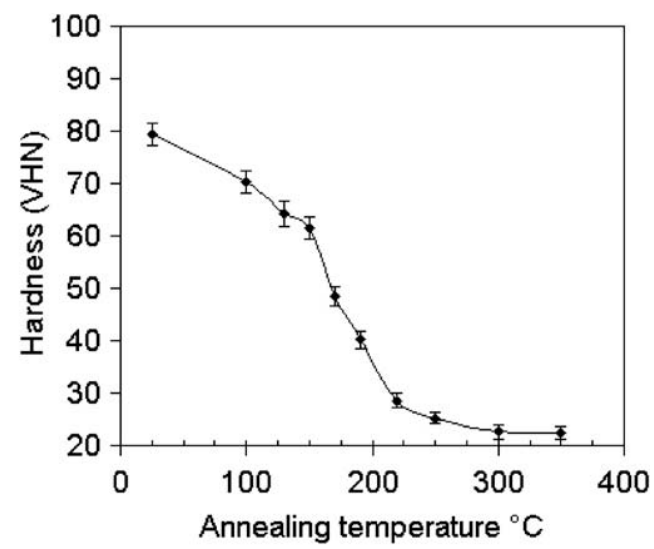

Fig. 4. Change in microhardness with annealing temperature, for $1 \mathrm{~h}$ isochronal treatments following plane-strain compression.

at $130{ }^{\circ} \mathrm{C}$ the grain thickness, $\lambda_{\mathrm{ND}}$, increased to $390 \mathrm{~nm}$ (Fig. 1b) but, although the HAGB spacing had more than doubled, the microstructure still largely retained its lamellar structure. Spheroidization of some of the smaller, lower-aspect-ratio grain fragments had, however, already started to take place (arrows in Fig. 1b and c). It was further evident from the BSE images in Fig. 1b that the lamellar boundaries were no longer as planar in appearance and some short-range HAGB migration had occurred, driven by the desire to locally equilibrate surface tensions at triple points. EBSD maps obtained from the ND-TD plane (Fig. 3) revealed that the thin lamellar grains started to spheroidize more rapidly in the transverse section, where they had a much lower initial aspect ratio $\left(\lambda_{\mathrm{TD}} / \lambda_{\mathrm{ND}}=2\right)$, and moved from the original lath form towards a more cigar-like morphology.

The results thus indicate that at low temperatures mainly two-dimensional coarsening and spheroidization of the structure first starts to occur in the transverse plane. There was little evidence of break up of the lamellar grains at this stage, i.e. there has been competitive growth between the ribbon without a significant reduction in their length, and a lamellar boundary structure is still maintained when viewed in the ND-RD plane. It was also evident, from inspection of the EBSD maps in Fig. 1, that the fraction of LAGBs simultaneously increased as coarsening of the structure occurred. This trend is confirmed below, where statistical data from the EBSD maps will be presented (see Section 3.3). On increasing the temperature to $150^{\circ} \mathrm{C}$, the HAGB boundary spacing further increased in ND (Fig. 1c), but now some of the lamellar grains started to break up, contributing to the reduction in overall grain aspect ratio. Break up of lamellar grain structures on annealing is driven by local imbalances in surface tension from the transverse LAGBs, causing the lamellar HAGBs to pinch-off, and subdividing the ribbon grains into shorter segments [18]. Examples of this behaviour can be seen in Figs. 1 and 2 (arrows). After annealing at $150^{\circ} \mathrm{C}$ most of the grains were dislocation free and the grain boundaries appeared well defined and free of defects (Fig. 2c).

\subsubsection{Higher annealing temperatures}

Raising the annealing temperature above $170{ }^{\circ} \mathrm{C}$ resulted in an accelerating increase in the average grain thickness (Fig. 5) and the grain aspect ratio progressively reduced. At higher temperatures the microstructure started to evolve discontinuously into bands of coarser, more equiaxed grains, mixed with surviving finer, elongated lamellar grains, and regions dominated by locally high densities of more finely spaced LAGBs and predominantly containing subgrains. Bands of concentrated LAGBs of such a coarse scale were not present in the starting deformation structure and evolved during coarsening of the initial lamellar structures. On annealing at progressively higher temperatures up to $220^{\circ} \mathrm{C}$, the bands of larger, low-aspect-ratio grains coarsened at a higher rate than the bands of subgrains, as well as expanding in width. Until, at $250^{\circ} \mathrm{C}$, the bands containing high concentrations of LAGBs were consumed and almost all the grains became equiaxed (Fig. 5c). This resulted in the appearance of a more homogeneous "recrystallized" grain structure. However, it should be noted that, even though the microstructure appeared "recrystallized", the larger equiaxed grains within the distribution contained many subgrains. Furthermore, coarsening continued to be accompanied by an increase in the relative area fraction of low-angle boundaries (Fig. 6b). 

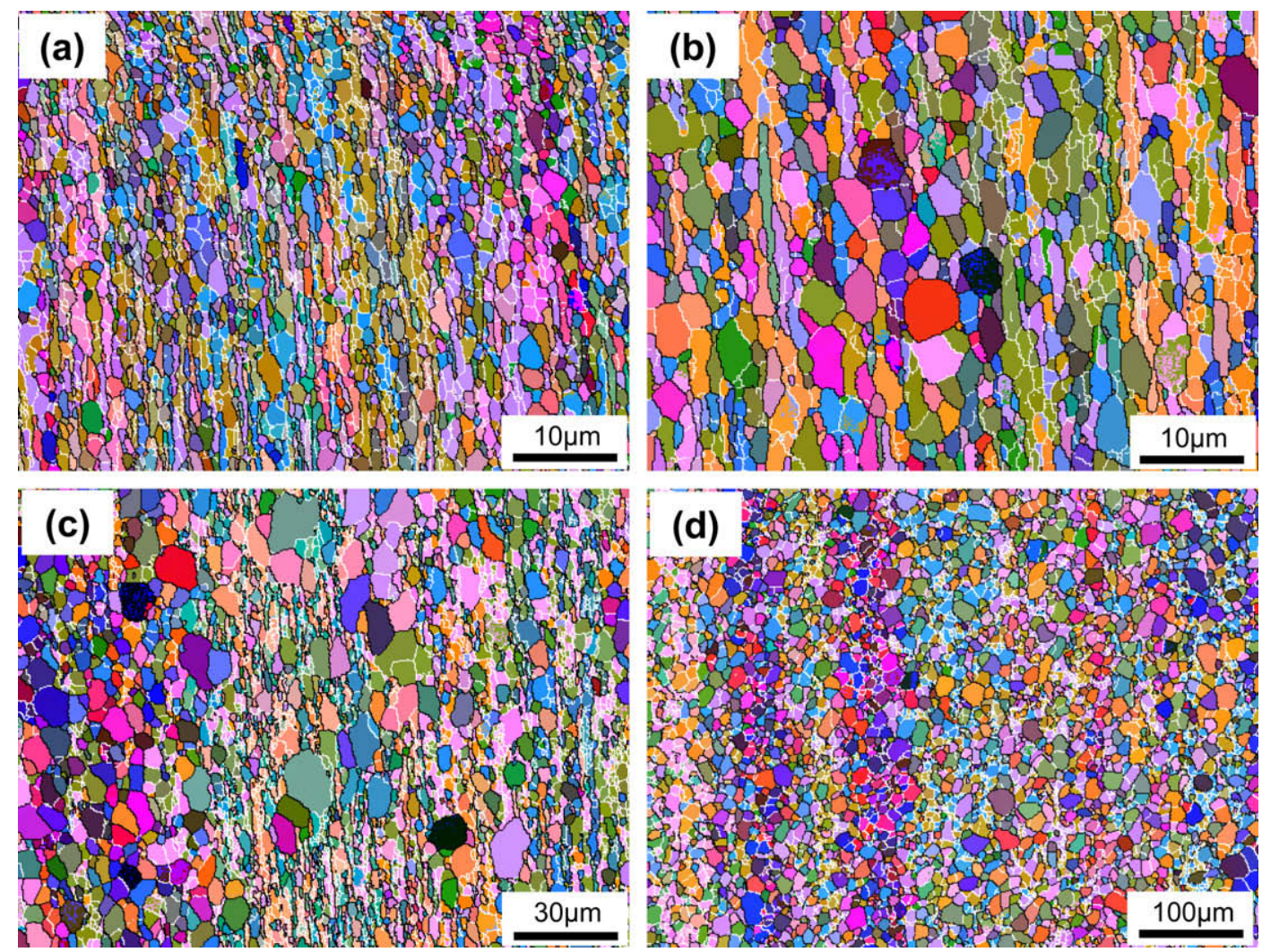

Fig. 5. EBSD maps of the grain structure of the Al-0.13\% Mg alloy, from the RD-ND plane, following annealing for $1 \mathrm{~h}$ at higher temperatures: (a) $170{ }^{\circ} \mathrm{C}$, (b) $190^{\circ} \mathrm{C}$, (c) $220^{\circ} \mathrm{C}$ and (d) $250^{\circ} \mathrm{C}$. Note the different scales.

\subsection{Statistical boundary data}

Fig. 6 shows plots of the mean grain thickness $\left(\lambda_{\mathrm{ND}}\right)$ and aspect ratio in the RD-ND and TD-ND planes, as well as the relative fraction of HAGB area, as a function of annealing temperature. In agreement with the hardness curves, it can be seen that there is a gradual increase in the HAGB spacing up to about $150^{\circ} \mathrm{C}$ and then the grain size rises very rapidly. The average grain aspect ratio in the ND-RD plane decreases quickly, but does not approach 1 until all the surviving lamellar grains and unrecrystallized bands are consumed, which only occurs after a relatively high annealing temperature is reached $\left(\sim 250^{\circ} \mathrm{C}\right)$.

An interesting observation was that the LAGB fraction progressively increased with annealing temperature, rather than decreased as would normally be expected during discontinuous recrystallization [17,31]. In Fig. $6 \mathrm{~b}$ it can be seen that the relative HAGB area, measured from the EBSD data, decreased from $83 \%$ in the deformed state to $59 \%$ at $200{ }^{\circ} \mathrm{C}$ and further declined to below $50 \%$ above $300{ }^{\circ} \mathrm{C}$. The relative fraction of LAGBs thus continued to grow at high temperatures, suggesting that a strong recrystallization texture is developed. Furthermore, in Fig. 7 a clear systematic shift in the boundary misorientation distributions can be seen with increasing temperature. In the asdeformed condition (Fig. 7a) a uniform spread of LAGB misorientations is seen, with a relatively low frequency, combined with a distribution of HAGBs increasing in frequency towards high misorientations. This misorientation distribution changes greatly on annealing with a progressive build up in misorientations below $15^{\circ}$, as the annealing temperature increases.

\subsection{Kinetics}

The grain coarsening kinetics were analyzed using the conventional grain growth law, given by:

$d_{t}^{n}-d_{0}^{n}=K t$

where $d_{0}$ and $d_{t}$ are the average grain size initially and after time $t$, and $K$ is the temperature-dependent rate constant [32]. From isothermal annealing at $250{ }^{\circ} \mathrm{C}$, using the $\lambda_{\mathrm{ND}}$ HAGB spacing, a reasonable fit could be obtained with a growth exponent of $1 / n=0.5$ (Fig. 8a) despite the fibrous lamellar starting structure. However, when the isochronal data was used to determine the activation energy from a $\left(\ln d_{t}^{2}-d_{0}^{2}\right)$ vs. $1 / T$ plot (Fig. 8b), it was found that the slope $(Q / R)$ changed with temperature. In Fig. $8 \mathrm{~b}$ the data suggests an apparent activation energy of $\sim 80 \mathrm{~kJ} \mathrm{~mol}^{-1}$ at low temperatures and a slope of $Q \sim 140 \mathrm{~kJ} \mathrm{~mol}^{-1} / \mathrm{R}$ above $200{ }^{\circ} \mathrm{C}$, which is close to that normally expected for grain coarsening in aluminium alloys [33]. In SPD-processed materials a change in $Q$ with temperature has been previously attributed to enhanced coarsening at low temperatures, 

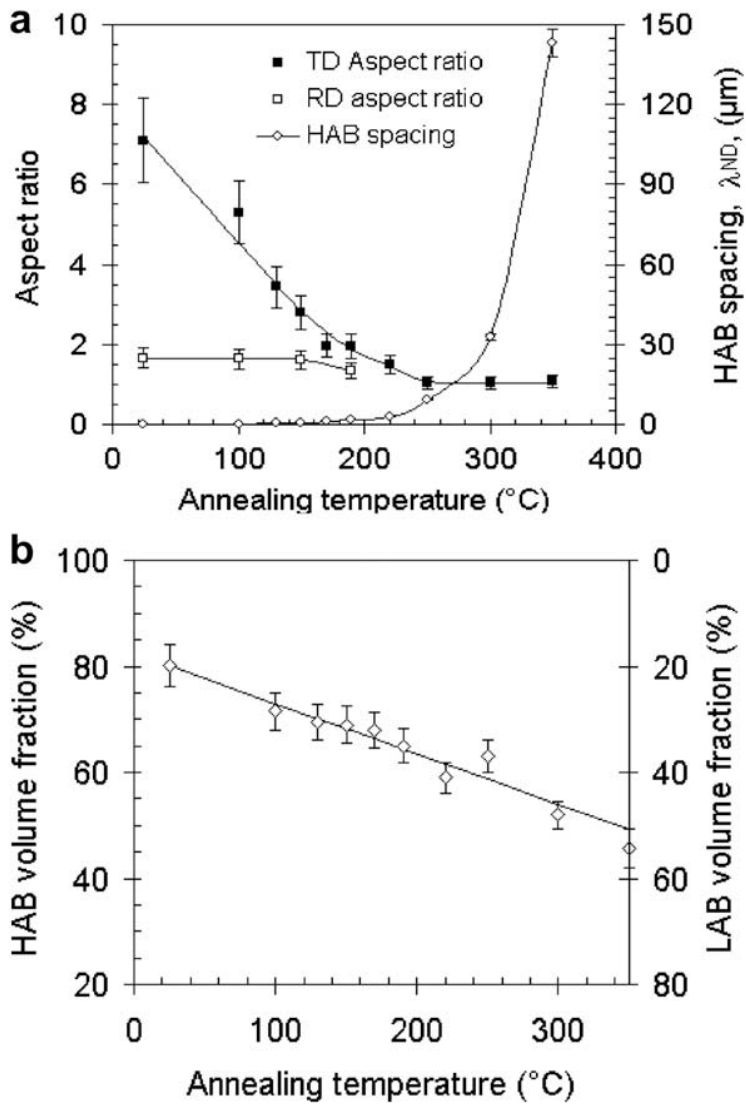

Fig. 6. Statistical data obtained from the EBSD maps showing: (a) the mean grain thickness $\left(\lambda_{\mathrm{ND}}\right)$ and aspect ratio in the RD-ND and TD-ND planes and (b) the relative fractions of high- and low-angle boundary area, as a function of annealing temperature.

caused by grain boundary diffusion associated with the presence of "non-equilibrium" grain boundaries in the deformed state [20]. The lower slope measured, of $80 \mathrm{~kJ} \mathrm{~mol}^{-1} / \mathrm{R}$, is consistent with that expected for grain boundary diffusion [34]. However, given the dramatic microstructural changes that occur in the temperature range studied, including a massive reduction in grain aspect ratio, increase in LAGB density and discontinuous coarsening, this appears an oversimplistic interpretation, and it is difficult to draw any unambiguous physical meaning from a diminished activation energy at low temperatures.

\subsection{Texture evolution}

$\left\{\begin{array}{lll}1 & 1 & 1\end{array}\right\}$ pole figures depicting the texture evolution as a function of annealing temperature are presented in Fig. 9. It has been shown previously that cryogenic PSC, of the same submicron-grained alloy, leads to the development of a conventional rolling texture with the overall texture intensity increasing with decreasing temperature and strain [12]. Here, peak intensities of up to $12 \times$ random were seen in the PSC sample deformed at $77 \mathrm{~K}$ to $\varepsilon_{\text {true }}=1.5$ (Fig. 9a). Rolling textures in aluminium alloys typically consist of a spread along the $\beta$ fibre between the Brass, $\left\{\begin{array}{llll}0 & 1 & 1\end{array}\right\}\left\langle\begin{array}{llll}2 & 1 & 1\end{array}\right\rangle$, and $\mathrm{Cu},\{225\}\langle 544\}$, orientations (e.g. [35]). At higher strains in PSC it was previously found that lowering the temperature favoured the development of a stronger Brass component at the expense of $\mathrm{Cu}$ and $\mathrm{S}$ [12]. However, at the lower PSC strain level used in this paper $S,\left\{\begin{array}{lll}1 & 2 & 3\end{array}\right\}\langle 634\rangle$, was the most dominant component $\left(f_{\mathrm{V}}=46 \%\right)$, followed by $\mathrm{Cu}$ $\left(f_{\mathrm{V}}=32 \%\right)$ and Brass $\left(f_{\mathrm{V}}=0.17 \%\right)$. As can be seen from Fig. 9, the texture does not initially change greatly on annealing, but as the temperature increases there is a reduction in Brass intensity and weak Cube, $\left\{\begin{array}{llll}0 & 0 & 1\end{array}\right\}\left\langle\begin{array}{llll}1 & 0 & 0\end{array}\right)$, and Goss, $\left\{\begin{array}{lll}0 & 1 & 1\end{array}\right\}\left\langle\begin{array}{lll}1 & 0 & 0\end{array}\right)$, components can be seen to emerge (Fig. 9d). These changes become more apparent when the main component volume fractions are plotted against annealing temperature. In Fig. 10 it can be seen that with increasing annealing temperature the Brass component reduces greatly in intensity from $\sim 20 \%$ to $5 \%$, while $\mathrm{Cu}$ rises slightly and there is a small loss of S. Other minor components also increase in intensity on annealing. The Goss and the Cube components rise at higher temperatures, above $130{ }^{\circ} \mathrm{C}$, when significant grain coarsening initiates, from very low initial levels of $f_{\mathrm{V}}<3 \%$, to $f_{\mathrm{V}} \sim 10 \%$ at $300{ }^{\circ} \mathrm{C}$.

The texture component maps in Fig. 11 illustrate some further interesting observations, in addition to the average trends plotted in Fig. 10. In the as-deformed condition (Fig. 11a) it can be seen that the main components present are $\mathrm{Cu}$ and $\mathrm{S}$, with a few Brass orientation grains. The lamellar grain fragments within a given region are most commonly comprised of only a limited number of texture components, either arranged alternately (e.g. $\mathrm{Cu}$ and $\mathrm{S}$ ), or interspersed with lamellar of random orientations. The texture bands are also frequently wider than the lamellar HAGB spacing, where they are arranged in layers of more than one texture variant of the same component, e.g. S. The smaller, low-aspect-ratio grain fragments present in the as-deformed material tend either to have random orientations, or to be from minor texture components (e.g. Goss). Furthermore, in the larger-area, lower-resolution map in Fig. 9e it can be seen that the main rolling orientations $\mathrm{S}$ and $\mathrm{Cu}$ can be locally concentrated on a coarse scale, with bands comprised predominantly of a high volume fraction of one texture component extending to widths of up to $20 \mu \mathrm{m}$. On annealing, the Brass lamellar grains progressively reduce in volume fraction (as noted above), but it is interesting that they do not appear to coarsen or spheroidize as readily as the $\mathrm{S}$ and $\mathrm{Cu}$ grains (arrows in Fig. 11c) and retain their high-aspect-ratio lamellar morphology to higher temperatures as they gradually disappear. It can also be seen that the small grain fragments of isolated Cube and Goss spheroidize early on and appear to gain a growth advantage as coarsening progresses, increasing in volume fraction with annealing temperature (arrows in Fig. 9b).

By averaging data from grains within the main texture components, small statistical differences also emerge from the general trends. In Fig. 12a it can be seen that in the starting material, grains of Brass orientation initially have the highest aspect ratio, whereas $\mathrm{S}$ have the least. The highaspect-ratio of the Brass grains is also retained to greater 

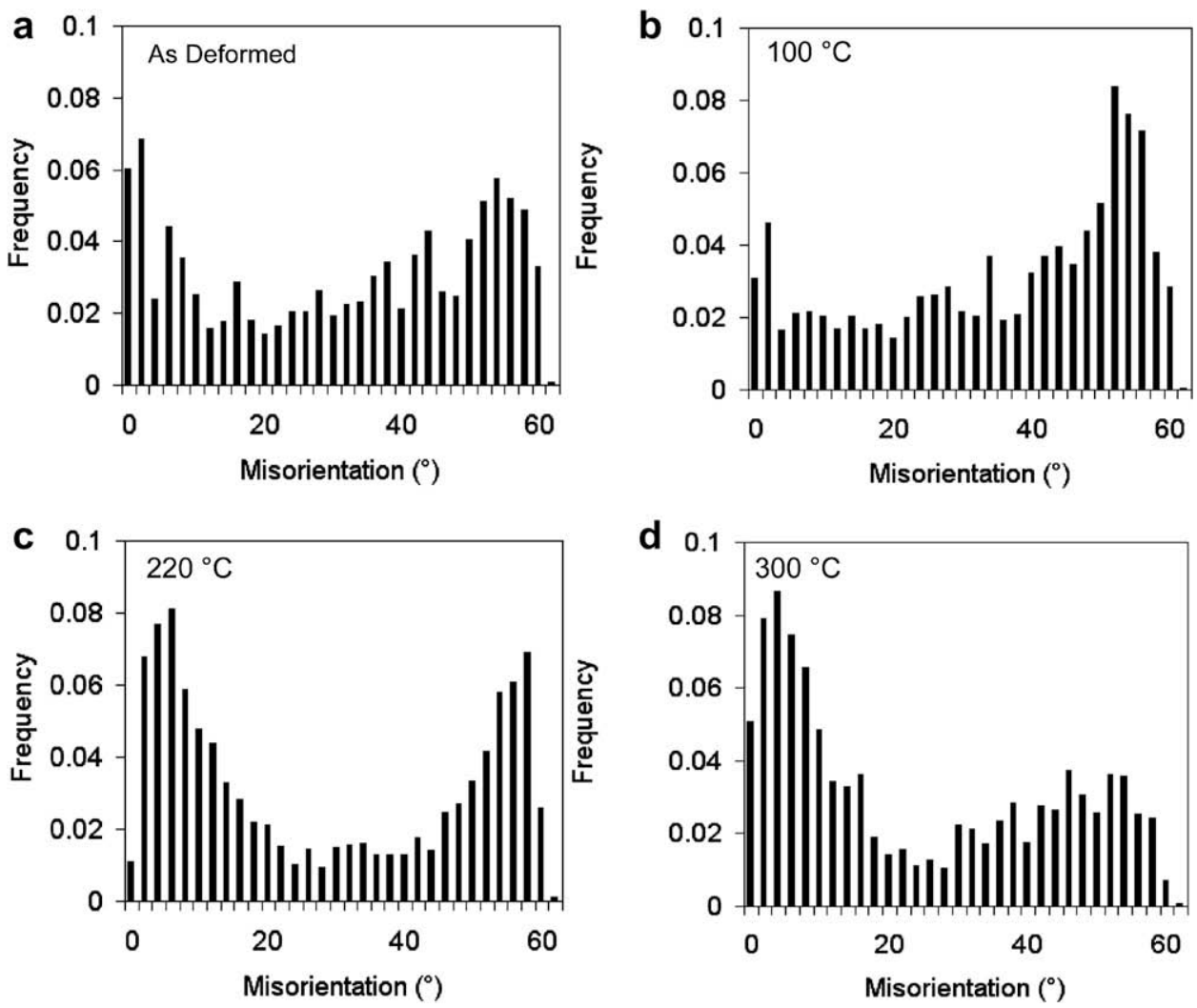

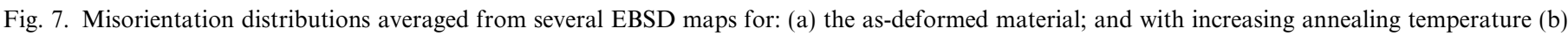
$100{ }^{\circ} \mathrm{C}$, (c) $200^{\circ} \mathrm{C}$ and (d) $300^{\circ} \mathrm{C}$.

temperatures than other components. This behaviour largely reflects the narrow nature of the Brass bands within the original deformation structure, which were generally only one lamellar HAGB spacing thick, and their higher stability on annealing. In comparison, the average data for all the grains, including the random and minor components, has a lower-aspect-ratio than for any of the main rolling components and reduces more rapidly, confirming a higher rate of spheroidization for the smaller, loweraspect-grain fragments. In Fig. $12 \mathrm{~b}$ we have further attempted to infer information, regarding the mobility of the boundaries surrounding particular texture components, by measuring their misorientation with their neighbours. It can be seen from this data that average misorientations all reduce on annealing and that the Copper component systematically has the highest misorientation boundaries, and Brass the lowest.

\section{Discussion}

In a recent review Gottstein et al. [36] have defined recovery, primary recrystallization and grain growth in terms of the underlying physics, i.e. recovery, involving the interaction and reorganization of dislocations and LAGBs, primary recrystallization on the basis of a mobile HAGB consuming the stored energy in the surrounding deformation structure, and grain growth involving curva- ture-driven migration of grain boundaries, constrained by the connected grain boundary system. However, in severely deformed alloys it is not always straightforward to apply these definitions. For example, because of the large density of high-angle boundaries already present in the deformed state, recrystallization does not generally occur by the growth of isolated nuclei into a surrounding deformed matrix. Furthermore, in dilute aluminium alloys, ultra-high deformation structures are typically cellular and contain relatively low levels of energy stored in the form of free dislocations $\left(0.1 \mathrm{MPa}\right.$; for $\rho \sim 10^{14} \mathrm{~m}^{-2}$ [3]) compared to the average surface energy $(\bar{\gamma})$ stored in the high density of high-angle boundaries (2-10 MPa for a 500-100 nm grain size [16]). Following ultra-high strain deformation, it has frequently been observed that the microstructure evolves uniformly with no discernible nuclei and this behaviour has been termed continuous recrystallization by a number of authors (e.g. [31,37]). Indeed, Humphreys has shown that a cellular structure will undergo uniform growth once $\sim 65 \%$ of all the boundaries are high angle in character [38]. In contrast, on annealing the cryogenically deformed submicron-grained SPD material studied, several overlapping stages of microstructure evolution were observed, which are summarized below.

(I) $<150{ }^{\circ} \mathrm{C}$ : recovery involving the sharpening of lowangle boundaries and a reduction in dislocation density. 

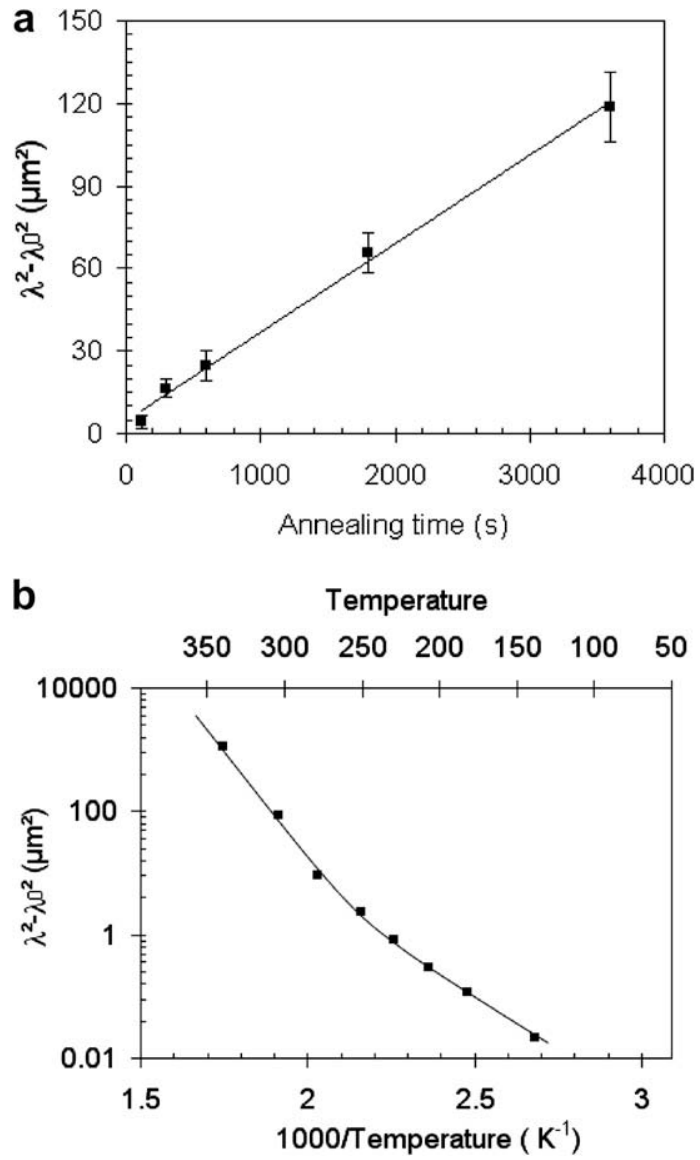

Fig. 8. Grain structure coarsening kinetics, based on the $\lambda_{\text {ND }}$ HAGB linear intercept measurement, showing: (a) good agreement with a grain growth exponent of 0.5 , on isothermal annealing at $250{ }^{\circ} \mathrm{C}$ and (b) a change in activation energy with annealing temperature.

(II) $100-150{ }^{\circ} \mathrm{C}$ : coarsening and spheroidization of the low-aspect-ratio grain fragments and ribbon grains in the transverse ND-TD plane, while largely maintaining the lamellar boundary structure.

(III) $150-200^{\circ} \mathrm{C}$ : break up and spheroidization of the lamellar grains in the ND-RD plane, with the Brass orientation lamellar grains resisting spheroidization to higher temperatures, but diminishing in volume fraction as coarsening progresses.

(IV) $190-220^{\circ} \mathrm{C}$ : rapid grain coarsening in bands containing high densities of mobile HAGBs and slow growth in bands of subgrains with low-mobility LAGBs, plus preferential growth of low-aspect-ratio Cube and Goss grains.

(V) $220-300^{\circ} \mathrm{C}$ : spread of the bands of HAGB-dominated coarse grains to consume the bands predominantly containing small subgrains, resulting in a fully recrystallized structure, but with a continuous increase in the relative fraction of LAGBs and the evolution of texture clusters.

During grain coarsening (stages II-V) it is interesting that a progressive increase in LAGB area fraction takes place, rather than the rapid decrease normally expected during discontinuous recrystallization. This behaviour is important as a build up of bands of high LAGB density within the micro-
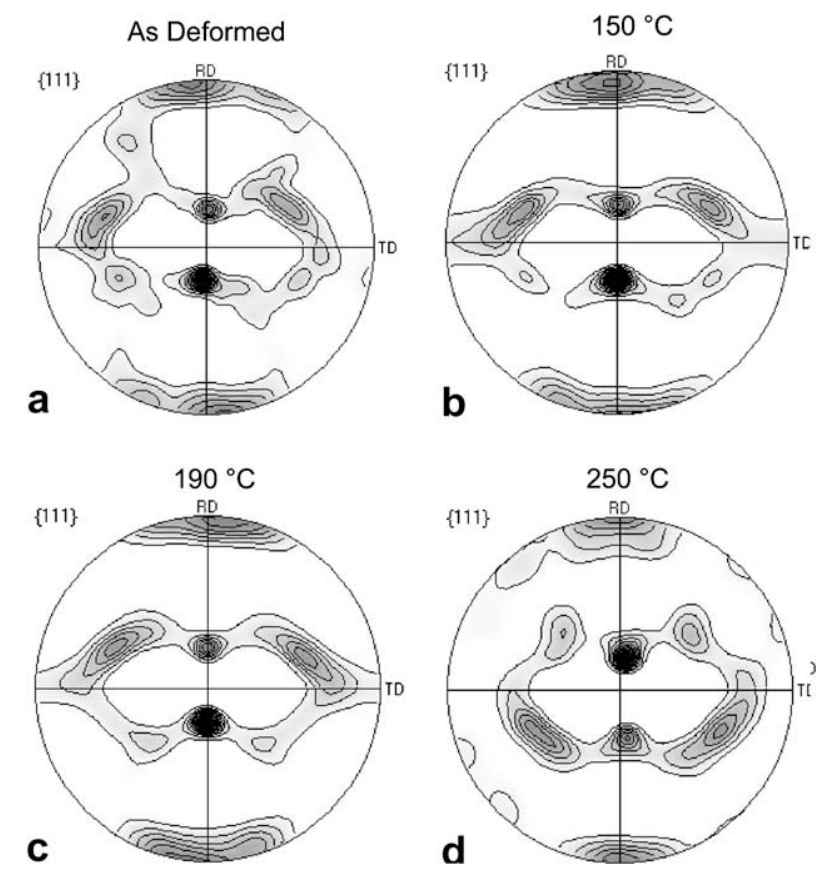

Fig. 9. Selected $\left\{\begin{array}{lll}1 & 1 & 1\end{array}\right\}$ pole figures illustrating the texture evolution with increasing annealing temperature: (a) after plane-strain compression in liquid nitrogen and following $1 \mathrm{~h}$ heat treatments at (b) $150^{\circ} \mathrm{C}$, (c) $190^{\circ} \mathrm{C}$ and (d) $250{ }^{\circ} \mathrm{C}$.

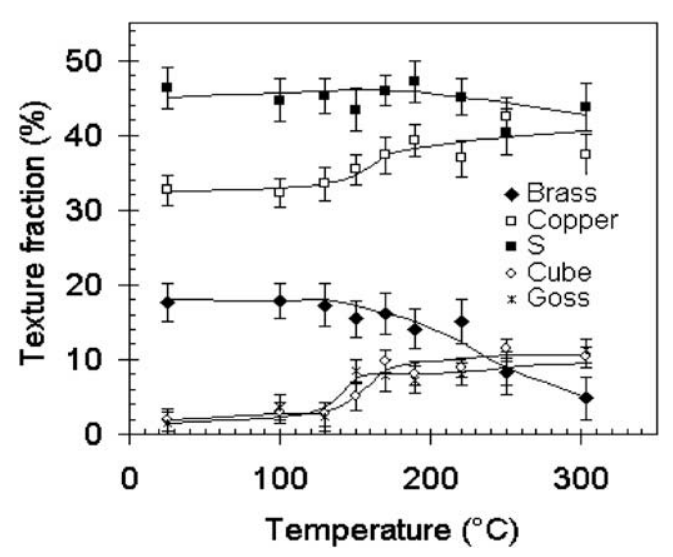

Fig. 10. Volume fractions of the main texture components plotted against annealing temperature.

structure leads to discontinuous coarsening, or primary recrystallization, at higher temperatures. This heterogeneous coarsening behaviour is clearly linked to the strong rolling texture in the starting material and produces a bimodal banded structure, at intermediate annealing temperatures. A similar phenomenon may explain the origin of the "bimodal grain structures" reported in the literature found in other cryogenically rolled alloys (e.g. $[13,14,39])$. However, measurement of the boundary misorientations shows that the bimodal structure seen here is better described as partially recrystallized and contains a mixture of regions of coarse grains and a fine subgrains (e.g. Fig. 5a). 

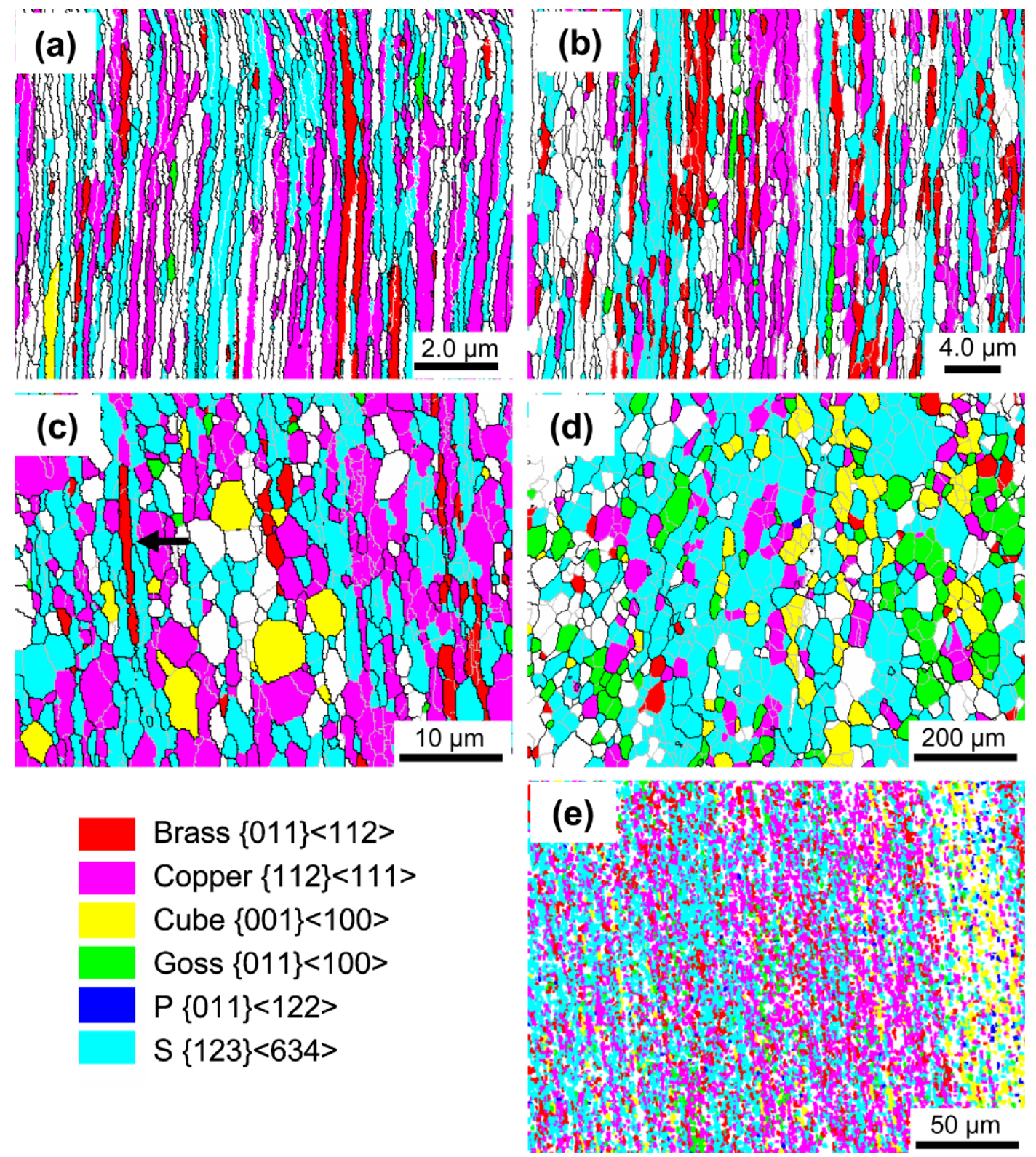

Fig. 11. Distributions of the main texture components within the EBSD maps: (a) the as-deformed material and with increasing annealing temperature (b) $150{ }^{\circ} \mathrm{C}$, (c) $190{ }^{\circ} \mathrm{C}$, (d) $300{ }^{\circ} \mathrm{C}$ and (e) a large-area map (annealed at $150{ }^{\circ} \mathrm{C}$ ) showing the texture concentrated in coarse scale bands.

\subsection{Low-temperature "2-D" coarsening and spheroidization of the lamellar structure}

The low-temperature stability of lamellar grain structures formed after high-strain ECAE processing has previously been studied and simulated by three-dimensional (3-D) Monte Carlo-Potts and 2-D vertex network models [18]. In this work the $\mathrm{Al}-3 \% \mathrm{Mg}$ alloy deformed at room temperature had a similar microstructure to that seen in the cryogenically deformed $\mathrm{Al}-0.1 \% \mathrm{Mg}$ alloy used here. In the early stages of annealing the modelling results showed that the relative density and misorientation of the transverse LAGBs played an important role in determining whether the ribbon grains broke up by "necking" along their length, leading to the collapse of the lamellar boundaries [31], or just slowly spheroidized during grain growth. In simulations this transition occurred for an initial grain aspect ratio of greater than 3 , but was sensitive to the spacing of the transverse boundaries and their misorientation $[18,40]$.

After cryogenic plane strain deformation the material studied had a very high-aspect-ratio lamellar grain structure. However, the spacing of the transverse boundaries, many of which had very low misorientations, was wider than the lamellar HAGB spacing. In agreement with the simulations reported previously [18], such a structure would be more resistant to break up by necking-off of transverse boundaries, and, as observed, would tend to first coarsen significantly by 2-D growth in the transverse (NDTD) plane, where the HAGB spacing had a lower-aspectratio $(\sim 2)$. Some necking-off of the high-aspect-ratio lamel- 

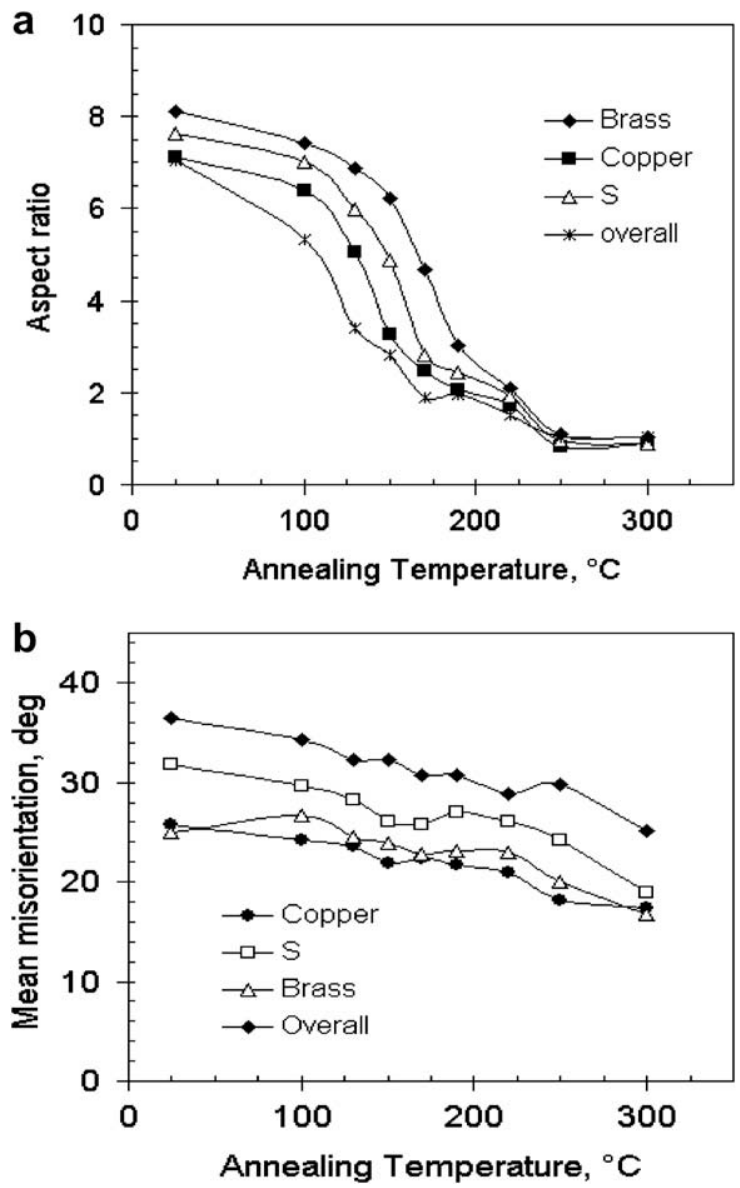

Fig. 12. Measurements from individual texture components showing: (a) the average grain aspect ratio for each component and (b) the mean misorientation of boundaries surrounding a particular component, with increasing annealing temperature.

lar grains was observed to occur locally as coarsening progressed, driven by imbalances of surface tension from higher misorientation transverse boundaries (e.g. arrows in Figs. 1 and 2c). However, considerable grain growth was first required before the lamellar grains spheroidized. In comparison, the smaller, lower-aspect-ratio grain fragments spheroidized relatively rapidly.

The early-stage 2-D coarsening of the HAGB lamellar structure will be influenced by imbalances in stored energy between neighbouring lamellar grains of different texture orientations, largely in the form of the energy density of the transverse LAGBs, but there will also be a more minor contribution from different dislocation densities within each band. During early-stage coarsening, ribbon grains of texture orientations containing higher levels of stored energy from LAGBs (i.e. with a greater ratio of $\bar{\gamma} / \bar{\lambda}$ ) should thus tend to disappear. However, the process is complicated by anisotropy in the mobility of the lamellar boundaries, which is sensitive to their misorientation. For example, the low-angle lamellar boundaries within the coarser fibrous grains retained in the deformation structure would be expected to have low mobilities. Such regions might be expected to grow out as annealing proceeds, but in fact the overall relative fraction of LAGBs was found to increase with annealing time and temperature (Fig. 6b); the reasons why this occurred will be examined further below.

\subsection{Texture evolution and discontinuous coarsening}

Research into the development of recrystallization textures, on annealing conventionally rolled (at room temperature) dilute fcc-Al alloys, deformed to moderate strains, has generally found that the rolling components (Brass, $\mathrm{Cu}, \mathrm{S}$ and Goss) reduce in strength, and there is an increase in the intensity of the Cube component and random orientations as recrystallization progresses $[32,41]$. The recrystallized grains typically grow from nuclei formed by recovery within the rolling components, at prior grain, or deformation band boundaries, as well as from random orientations within shear bands and by particle-stimulated nucleation $[32,41]$, whereas cube nuclei predominantly grow from transition, or cube, bands $[42,43]$. In contrast to discontinuous recrystallization, where the relative proportion of HAGB area rapidly rises [19,31], during continuous recrystallization the deformation texture is normally retained and there is usually little change in the HAGB area fraction $[31,44]$. However, in the results reported here, after cryogenic PSC of a severely deformed submicron-grained alloy, as well as a large progressive increase in the fraction of LAGBs (Fig. 6b), it has further been found that there were significant changes in texture on annealing. This included the near complete loss of the Brass component and a modest rise in Cube and Goss at high temperatures (Fig. 10), combined with a small reduction in $\mathrm{S}$ and increase in $\mathrm{Cu}$ strength as annealing progresses.

\subsubsection{The effect of texture clustering}

A number of investigations have predicted changes in the distribution of boundary misorientations during grain coarsening, and an increase in the density of LAGBs associated with a strong texture present in the starting material [45-47]. In a randomly textured polycrystal, when two grains meet during growth, the resulting boundary will be near the mean misorientation and any low-angle boundary that does form is likely to be surrounded by high-angle boundaries, which can sweep past less mobile boundaries. In the case of an idealized two-component texture, the possibility exists for the development of very low-angle, or very high-angle, boundaries. However, on average a minor component " $\mathrm{A}$ " embedded in a matrix of the major component " $\mathrm{B}$ " will have more A-B high-mobility boundaries per unit volume, resulting in it growing more rapidly and leading to oscillations in the volume fractions of the two components $[45,46]$. Ma et al. have shown that if a single texture component is embedded in a random matrix the results depend on the anisotropy of boundary energy and mobility, with misorientation, as well as the initial dispersion of the textured grains [46]. In their simulations it was found that texture clustering inevitably occurs during 
coarsening, with the volume fraction of the embedded texture component increasing, or decreasing, depending on its energy density relative to that of the matrix. More importantly, in the current context, texture clustering was found to result in an increase in the density of LAGBs. A similar behaviour has been predicted by Holm et al. in a strong single-component texture system, where the formation and growth of clusters of low-misorientation boundaries caused the misorientation distribution to shift to lower angles [47].

Following cryogenic PSC, the deformation structures were dominated by bands of a limited number of texture components (Fig. 11a). In addition, the texture components were concentrated heterogeneously on a scale coarser than the ribbon grain structure present in the deformed material (Fig. 11e). Because of the limited number of texture components, and their variant orientations present in the deformed state, during annealing lamellar grains with a growth advantage over their neighbours will expand sideways and eventually encounter a grain of a similar orientation, forming a new LAGB by orientation impingement. As many grains of similar texture were in close proximity (e.g. Fig. 11a) the frequency of encounter will be great and bands will develop with a high density of low-angle boundaries, within a given region of the microstructure. Furthermore, the mobility of boundaries with misorientations below $15^{\circ}$ falls off rapidly and, after impingement with bands of similar orientation, migrating lamellar boundaries will lose their mobility due to "orientation pinning" [48]. This will result in the net progressive increase in LAGB area fraction, observed as annealing progresses (Fig. 10). The bands that consequently develop containing mainly LAGBs will also coarsen more slowly and the boundary structure in such regions will gradually spheroidize to form subgrains. In comparison, local volumes that contain grains of a mixture of texture components and a higher fraction of HAGBs will coarsen more rapidly, leading to discontinuous coarsening and the development of an apparent bimodal "grain structure". The HAGB regions will then expand, consuming the bands containing mainly LAGBs, because a disparity will develop in stored energy, due to the increasing differential in cell size between the two regions [46]. Although at higher temperatures the texture bands appear to break up as spheroidization and grain growth becomes more advanced, the texture clusters will dynamically evolve as more rapidly growing grains will continuously encounter volumes of similar orientation forming new LAGBs, which then inhibit their growth. On average the grain growth kinetics would be expected to be slower than for a randomly textured system and it is normally expected that this will lead to a reduction in the grain growth exponent $[46,47]$. However, this was not observed.

\subsubsection{Increase in the Cube and Goss components}

At higher annealing temperatures the results in Figs. 911 show a significant progressive increase in the volume fraction of Cube- and Goss-orientated grains as microstructural coarsening progresses. Studies on conventionally deformed aluminium alloys have shown that after recovery the Cube and Goss components tend to contain lower levels of stored energy than the rolling components [41,49], which would normally be expected to give them a growth advantage relative to their neighbours. Here, Cube- and Goss-orientated grains originated from isolated, lowaspect-ratio smaller grain fragments, within the starting deformation structure, and contained few internal LAGBs (e.g. Fig. 11a). In addition, the Cube and Goss grains were mainly imbedded in an $\mathrm{S}$ - and $\mathrm{Cu}$-orientated matrix. This could theoretically result in the Cube grains having greater boundary mobility, owing to the potential for forming special $40^{\circ}\left\langle\begin{array}{llll}1 & 1 & 1\end{array}\right\rangle \sum 7$ boundaries with $\mathrm{S}$ [50]. However, more significant is the fact that, because grains of these orientations were from isolated minor texture components, they exemplify the scenario disused above for a dilute idealized two-component texture [45], i.e. during growth they rarely encounter neighbouring grains of a similar orientation and thus do not become orientation pinned by forming texture clusters comprised of low-mobility LAGBs.

\subsubsection{Loss of the Brass component}

The Brass texture component was found to progressively diminish during annealing the cryogenically deformed samples (Fig. 10). Furthermore, the Brass grains tended to retain their lamellar character (Fig. 11) and high-aspect-ratio to greater temperatures than grains of other orientations (Fig. 12a). The reduction in the volume fraction of the Brass component during annealing severely deformed aluminium alloys has also been reported in several other studies (e.g. [51,52]). Quadir et al. have related this effect to Gottstein et al.'s ReNuc model $[36,41]$, developed for conventional coarse-grained materials. This model predicts that the Brass orientation recovers more slowly than other texture components, reducing the likelihood of viable Brass nuclei, and the Brass component is then consumed by other orientations. This argument is based on the lower number of active slip systems for the Brass orientation, contributing to the generation of well-defined cell bands within large deformed grains at moderate strains. However, it seems unlikely that this theory is applicable to the nanolamellar HAGB grain structures seen in the alloy investigated here. Overall, most research concludes that the Brass orientation has lower stored energy than the other rolling components [41,53], which would be expected to give the lamellar Brass grains a growth advantage during coarsening. Furthermore, due its lower volume fraction and more dispersed nature, Brass-oriented lamellar grains would be less likely to have their growth inhibited by texture clustering. In Fig. 12b the Brass ribbon grains were found to have the lowest average boundary misorientation with their neighbours $\left(25^{\circ}\right)$ of all the rolling components. However, in this range there would not be a great effect on boundary mobility $[32,40]$. Currently the high stability and disappearance of the Brass-orientated grains cannot, thus, be easily explained, and requires a more accurate investigation of the statistical substructural parameters within the Brass ribbon grains, relative to the other orientations. 


\section{Conclusions}

The grain structure and texture evolution during annealing an $\mathrm{Al}-0.13 \% \mathrm{Mg}$ submicron-grained alloy, preprocessed by ECAE and subsequently deformed by PSC at cryogenic temperatures to obtain a nanoscale lamellar grain structure, has been investigated by TEM and EBSD. Despite the high initial fraction of HAGBs present after deformation, the fraction of LAGBs progressively increased during annealing, to greater than $50 \%$ above $300{ }^{\circ} \mathrm{C}$, leading to instability and discontinuous coarsening/recrystallization. At intermediate temperatures this resulted in a similar microstructure to the "bimodal grain structure" reported in other annealed, cryogenically rolled nanograined metals. However, here it was found to be better described as a partially recrystallized structure comprised of bands of coarser grains and fine subgrains.

The surprisingly large increase in LAGB area fraction on annealing, and associated evolution of an apparent bimodal "grain" structure, has been shown to be caused by orientation clustering during grain growth, resulting in "orientation pinning", by the formation of new low-angle boundaries. This behaviour is related to the strong deformation texture induced in the starting material by PSC in liquid nitrogen.

After PSC the material had a strong conventional rolling texture, which evolved to give a large reduction in the Brass component and a rise in Cube and Goss at higher temperatures. The increase in intensity of the Cube and Goss components occurred because they originated from minor isolated grains in the deformed state. During growth, they thus rarely encountered neighbouring grains of a similar orientation and their growth rate was not inhibited by forming texture clusters comprised of low-mobility LAGBs. The observed reduction in the Brass component could not be reconciled with the existing consensus on its relative stored energy and theories of the evolution of different texture components in conventional rolling.

\section{Acknowledgements}

G.H.Z. would like to acknowledge the financial support of the Higher Education Commission of Pakistan for this research. This work was partly supported through the University of Manchester EPSRC Light Alloys Portfolio Partnership (EP/D029201/1).

\section{References}

[1] Hayes JS, Kyte R, Prangnell PB. Mater Sci Tech 2000;16:1259.

[2] Furukawa M, Iwahashi Y, Horita Z, Nemoto M, Tsenev NK, Valiev RZ, et al. Acta Mater 1997;45:4751.

[3] Valiev ZR, Islamgaliev RK, Alexandrov IV. Prog Mater Sci 2000; 45:103.

[4] Segal VM. Mater Sci Eng A 1999;271:322.

[5] Bowen JR, Prangnell PB, Humphreys FJ. Mater Sci Tech 2000; 16:1246.

[6] Saito Y, Utsunomiya H, Sakai T. Acta Mater 1997;47:579.
[7] Zhilyaev AP, Swisher DL, Oh-ishi K, Langdon TG, McNelley TR. Mater Sci Eng A 2006;429:137.

[8] Hebesberger T, Stüwe HP, Vorhauer A, Wetscher F, Pippan R. Acta Mater 2005;53:393.

[9] Pippan R, Wetscher F, Hafok M, Vorhauer A, Sabirov I. Adv Eng Mater 2006;8:1046.

[10] Pippan R, Vorhauer A. Metall Mater Trans 2008;39:417.

[11] Prangnell PB, Huang Y, Berta M, Apps PJ. Mater Sci Forum 2007;550:159.

[12] Huang Y, Prangnell PB. Acta Mater 2008;56:1619.

[13] Wang YM, Chen YM, Zhou F, Ma E. Nature Lett 2002;419:912.

[14] Wang YM, Ma E. Acta Mater 2004;52:1699.

[15] Subramanya Sarma V, Sivaprasad K, Sturm D, Heilmaier M. Mater Sci Eng A 2008;489:253.

[16] Driver JH. Scripta Mater 2001;51:819.

[17] Prangnell PB, Berta M, Apps PJ, Bate PS. Mater Sci Forum 2004;467-470:1261

[18] Prangnell PB, Hayes JS, Bowen JR, Apps PJ, Bate PS. Acta Mater 2004;52:3193.

[19] Gholinia A, Bowen JR, Hayes JS, Wang ZC, Prangnell PB. In: Hansen $\mathrm{N}$ et al., editors. Recrystallisation - fundamental aspects and relations to deformation microstructure. Denmark: Risø; 2000. p. 345.

[20] Wang J, Furukawa M, Horita Z, Nemoto M, Valiev RZ, Langdon TG. Mater Sci Eng A 1996;216:41.

[21] Lian J, Vailev RZ, Baudelet B. Acta Metall Mater 1995;43:4165.

[22] Morris DG, Muñoz-Morris MA. Acta Mater 2001;50:4047.

[23] Molodova X, Gottstein G. Mater Sci Forum 2008;584-586:944.

[24] Molodova X, Gottstein G, Winning M, Hellmig RJ. Mater Sci Eng A 2007;460:204

[25] Vandermeer RA, Hansen N. Acta Mater 2008;56:5719.

[26] Mishin OV, Godfrey A. Metall Mater Trans A 2008;39:2923.

[27] Hasegawa H, Komura S, Utsunomiya A, Horita Z, Furukawa M, Nemoto M, et al. Mater Sci Eng A 1999;265:188.

[28] Segal VM. Mater Sci Eng A 1995;197:157.

[29] Huang Y, Humphreys FJ. Mater Character 2001;47:235.

[30] Apps PJ, Berta M, Prangnell PB. Acta Mater 2005;53:499.

[31] Jazaeri H, Humphreys FJ. Acta Mater 2004;52:3251.

[32] Humphreys FJ, Hatherly M. Recrystallization and related annealing phenomena. 2nd ed. Amsterdam: Elsevier; 1995.

[33] Huang Y, Humphreys FJ. In: Gottstein G, Molodov DA, editors. Recrystallization and grain growth 1. Berlin: Springer Verlag; 2001. p. 409.

[34] Frost HJ, Ashby MF. Deformation maps. Oxford: Pergamon Press; 1982.

[35] Engler O, Hirsch J, Lücke K. Acta Metall 1989;37:2743.

[36] Gottstein G, Shvindlerman LS, Crumbach M, Barrales-Mora LA. Mater Sci Forum 2007;558:3.

[37] Oscarsson A, Ekström H-E, Hutchinson B. Mater Sci Forum 1993;113-115:177.

[38] Humphreys FJ, Prangnell PB, Bowen JR, Gholinia A, Harris C. Philos Trans Roy Soc Lond 1999;357A:1663.

[39] Gang UG, Park DB, Nam WJ. Mater Sci Forum 2007;558-559:735.

[40] Huang Y, Humphreys FJ. Acta Mater 2000;48:2017.

[41] Crumbach M, Goerdeler M, Gottstein G. Acta Mater 2006;54:3291.

[42] Ridha AA, Hutchinson WB. Acta Metall 1982;30:1929.

[43] Samajdar I, Doherty RD. Scripta Metall Mater 1995;32:845.

[44] Engler O, Huh M-Y. Mater Sci Eng A 1999;271:371.

[45] Abbruzzese G, Lücke K. Acta Metall 1988;36:55.

[46] Ma N, Kazaryan A, Dregia SA, Wang Y. Acta Mater 2004;52:3869.

[47] Holm EA, Hassold GN, Miodownik MA. Acta Mater 2001;49:2981.

[48] Juul Jensen D. Acta Metall Mater 1995;43:4117.

[49] Guiglionda G, Borbély A, Driver JH. Acta Mater 2004;52:3413.

[50] Theyssier MC, Driver JH. Mater Sci Eng A 1999;272:73.

[51] Quadir MZ, Al-Buhamad O, Bassman L, Ferry M. Acta Mater 2007; 55:5438.

[52] Mishin OV, Jul Jensen D, Hansen N. In: Hirsch J, Skrotzki B, Gottstein G, editors. Aluminium alloys ICAA11. Weinheim: WileyVCH; 2008. p. 114.

[53] Rajmohan N, Szpunar JA. Mater Sci Tech 1999;15:1259. 